\title{
Pulmonary intestinal-type adenocarcinoma does not show enteric differentiation by immunohistochemical study
}

\author{
Samuel A Yousem \\ Department of Pathology, University of Pittsburgh School of Medicine, Pittsburgh, PA, USA
}

\begin{abstract}
Six cases of an unusual variant of primary pulmonary adenocarcinoma resembling colorectal and sinonasal adenocarcinoma are presented. Pulmonary intestinal-type adenocarcinoma occurs in elderly Caucasians and is associated with a histology characteristic of colorectal/enteric adenocarcinoma: a garland-like architecture with a 'gland in gland' periphery, central 'dirty' necrosis, and elongated stratified columnar cells, lacking significant goblet or signet ring differentiation. While a resemblance to intestinal adenocarcinoma by light microscopy is present, immunohistochemical studies comparing these carcinomas with metastatic colorectal adenocarcinoma clearly show a respiratory phenotype with the neoplastic cells expressing thyroid transcription factor-1 and cytokeratin 7 to the exclusion of cytokeratin 20, and failing to express CDX-2. Stains for a variety of epithelial mucins (MUC1, MUC2, MUC5AC) also support this observation. The differential diagnosis with other pulmonary adenocarcinomas, especially those with mucinous differentiation, is discussed.
\end{abstract}

Modern Pathology (2005) 18, 816-821, advance online publication, 17 December 2004; doi:10.1038/modpathol.3800358

Keywords: intestinal carcinoma; colorectal; sinonasal

The morphologic spectrum of pulmonary adenocarcinomas is extremely broad and has been recognized in recent classification schemes. ${ }^{1}$ Primary lung tumors that show mucinous or enteric differentiation are rare and their exact classification remains controversial. $^{2,3}$ Within this group are mucinous cystic tumors including mucinous cystadenocarcinoma, mucinous (colloid) carcinoma, mucinous variants of bronchioloalveolar carcinoma, and signet ring cell carcinoma. ${ }^{2,4-11}$ The histologic and differentiation characteristics of these tumors overlap with gastrointestinal malignancies, especially colorectal carcinoma, including variants initially reported as 'enteric' carcinoma of the lung. ${ }^{12-15}$ This current study reports six cases of intestinal-type adenocarcinoma of lung, morphologically similar to high-grade sinonasal adenocarcinoma of the intestinal type, and examines the differential expression of recently characterized immunohistochemical markers associated with colorectal and lung tumors including CDX-2, TTF-1, MUC1, MUC2, MUC5, cytokeratin 7 (CK7), and cytokeratin 20 (CK20). CDX-2 is a homeobox gene related to the Drosophila

Correspondence: Dr SA Yousem, MD, Department of Pathology A610, UPMC - Presbyterian, 200 Lothrop Street, Pittsburgh, PA 15213-2582, USA.

E-mail: yousemsa@upmc.edu

Received 5 October 2004; revised 18 November 2004; accepted 19 November 2004; published online 17 December 2004 caudal gene that encodes a nuclear transcription factor involved in the induction of intestine-specific genes, from esophagus to rectum, including the pancreatobiliary system. ${ }^{16}$ It represents a highly specific marker for both primary and metastatic intestinal adenocarcinomas, although it has been reported to be expressed in 13\% of lung adenocarcinomas and some nongastrointestinal adenocarcinomas, such as sinonasal intestinal-type adenocarcinomas. ${ }^{13-15,17}$ Of primary lung tumors, colloid adenocarcinoma is most expressive of CDX$2 .^{3-7}$ TTF-1 is a 38-Kd homeodomain gene containing a DNA binding protein originally identified in follicular cells of the thyroid as a regulator of thyroid-specific genes, and was subsequently observed in respiratory epithelial cells. ${ }^{18,19}$ Expression of this nuclear protein in adenocarcinomas outside of the lung and thyroid is extremely rare. ${ }^{20}$ MUC1, 2, and 5 are secretory mucins variably expressed in the gastrointestinal and respiratory tracts. ${ }^{21-26}$ The expression of or absence of epithelial intermediate filaments CK7 and CK20 are commonly utilized to separate colorectal from other primary adenocarcinomas especially lung. ${ }^{27-29}$ The six cases of primary pulmonary intestinal-type adenocarcinomas were compared to age- and sex-matched metastatic colonic adenocarcinomas of lung to investigate their staining properties with regard to these antigens and their applicability to the differential diagnosis. 


\section{Materials and methods}

Six cases of pulmonary intestinal-type adenocarcinoma were identified in a review of 430 primary adenocarcinomas of lung accessioned between 1996 and 2004 at the University of Pittsburgh Medical Center-Presbyterian campus. A total of 10 additional age- and sex-matched cases of surgically resected metastatic colonic adenocarcinomas to lung were utilized for immunohistochemical comparison to the study group.

Tissue was fixed in 10\% neutral-buffered formalin and paraffin embedded. Antibodies used for this study are listed in Table 1. Immunohistochemical staining using the avidin-biotin complex and peroxidase methods was performed on $4 \mu \mathrm{m}$ sections using previously described methods. ${ }^{30}$ Appropriate negative and positive controls were included.

A semiquantitative grading system of percentage of cell staining was used to yield quartile scores of $0-4: 0,1-4 \% ; 1,5-24 \% ; 2,25-49 \% ; 3,50-74 \%$; and 4, $75-100 \%$.

All patients had colonoscopy, abdominal CT scans, and barium enemas prior to or after thoracic surgery that excluded metastatic gastrointestinal adenocarcinoma.

\section{Results}

Clinical data on the six patients are shown in Table 2. Patients were elderly with an average age of 69.8 years (range 57-82) with a female predilection (female/male $=4 / 2$ ) and all were Caucasian. All six were cigarette smokers. None had a history of exposure to wood dust. Owing to persistent cough $(N=4)$, hemoptysis $(N=2)$, chest pain $(N=3)$, and postobstructive pneumonia $(N=1)$, the patients presented for radiologic examination, which in all cases revealed a solitary spiculated mass suspicious for malignancy. Interestingly in five of the six cases, the tumor was localized to the right upper lobe. In four cases, lobectomy was performed with pneumonectomy and segmental resection in the remaining two.

Grossly, the tumors were well-demarcated peripheral tumors described as 'white/gray' firm masses with foci of yellow punctate necrosis $(N=3)$. Diameters ranged from 1.5 to $7.0 \mathrm{~cm}$ (average $3.7 \mathrm{~cm})$.

The adenocarcinomas had the characteristic garland pattern of infiltration associated with colorectal adenocarcinomas with cystic glandular structures containing mucin and necrotic debris encircled by an array of round tubular glands (Figure 1). A cribriform 'gland in gland' pattern was present in each case with lumina filled with necrotic epithelial cells, fibrin, neutrophils, and karyorrhectic debris, enmeshed in extracellular mucin (Figure 2). Such 'dirty necrosis' was seen in all cases and was often accompanied by segmental necrosis of the glandular lining (Figure 3). The glands were lined by stratified tall columnar absorptive-like cells with modest amounts of apically oriented amphophilic cytoplasm. Their hyper-

Table 1 Antibodies utilized in the study of pulmonary intestinal-type adenocarcinomas

\begin{tabular}{|c|c|c|c|c|}
\hline Antigen & Antibody (clone) & Source & Dilution & Antigen retrieval ${ }^{\text {a }}$ (yes/no) \\
\hline $\mathrm{TTF}-1$ & $8 \mathrm{G} 7 \mathrm{G} 3 / 1^{\prime}$ & Dako, Carpinteria, CA, USA & $1: 25$ & Yes \\
\hline CDX-2 & CDX2-88 & Biogenex, San Ramon, CA, USA & $1: 100$ & Yes \\
\hline CK7 & OV-TL 12/30 & Dako, Carpinteria, CA, USA & $1: 100$ & Yes \\
\hline CK20 & Ks20.8 & Dako, Carpinteria, CA, USA & $1: 20$ & Yes \\
\hline MUC1 & Ma695 & Vector Labs, Burlingame, CA, USA & $1: 200$ & Yes \\
\hline MUC2 & M53 & NeoMarkers, Fremont, CA, USA & $1: 100$ & Yes \\
\hline MUC5AC & 45M1 & NeoMarkers, Fremont, CA, USA & $1: 25$ & Yes \\
\hline
\end{tabular}

${ }^{\mathrm{a} A n t i g e n ~ r e t r i e v a l ~ v i a ~ p r e s s u r e ~ c o o k e r . ~}$

Table 2 Clinicopathologic data on pulmonary intestinal-type adenocarcinomas

\begin{tabular}{cccccccc}
\hline Case \# $\begin{array}{c}\text { Age/sex/ } \\
\text { race (years) }\end{array}$ & Procedure Location & $\begin{array}{l}\text { Size } \\
\text { (cm) } \begin{array}{l}\text { Visceral } \\
\text { pleural } \\
\text { invasion }\end{array}\end{array}$ & $\begin{array}{c}\text { Angio-lymphatic } \\
\text { invasion }\end{array}$ & $\begin{array}{c}\text { N1 node } \\
\text { involvement }\end{array}$ & N2 node involvement & TNM stage Status \\
\end{tabular}

\begin{tabular}{|c|c|c|c|c|c|c|c|c|c|c|}
\hline 1 & $74 / \mathrm{F} / \mathrm{W}$ & $\mathrm{P}$ & RUL & 3.6 & - & + & + & _- & T2N1M0 & DOD, $26 \mathrm{mo}$ \\
\hline 2 & $70 / \mathrm{F} / \mathrm{W}$ & $\mathrm{L}$ & RUL & 1.7 & + & - & + & - & T2N1M0 & DOD, $18 \mathrm{mo}$ \\
\hline 3 & $82 / \mathrm{M} / \mathrm{W}$ & $\mathrm{L}$ & RUL & 6.5 & + & + & - & - & T2NoM0 & DNED, $5 \mathrm{mo}$ \\
\hline 4 & $63 / F / W$ & $\mathrm{~L}$ & RUL & 1.5 & - & - & - & - & T1N0M0 & ANED, $7 \mathrm{mo}$ \\
\hline 5 & 73/F/W & $\mathrm{L}$ & LLL & 7.0 & - & + & + & - & T2NoM0 & ANED, 3 mo \\
\hline 6 & $57 / \mathrm{F} / \mathrm{W}$ & $\mathrm{S}$ & RUL & 2.0 & + & + & - & - & T2NoM0 & ANED, 2 mo \\
\hline
\end{tabular}

W-Caucasian; M-male; F-female; P-pneumonectomy; L-lobectomy; S-segmentectomy; RUL—right upper lobe; LLL—left lower lobe; DOD—dead of disease; DNED—dead, no evidence of disease; ANED—alive, no evidence of disease; mo-months. 


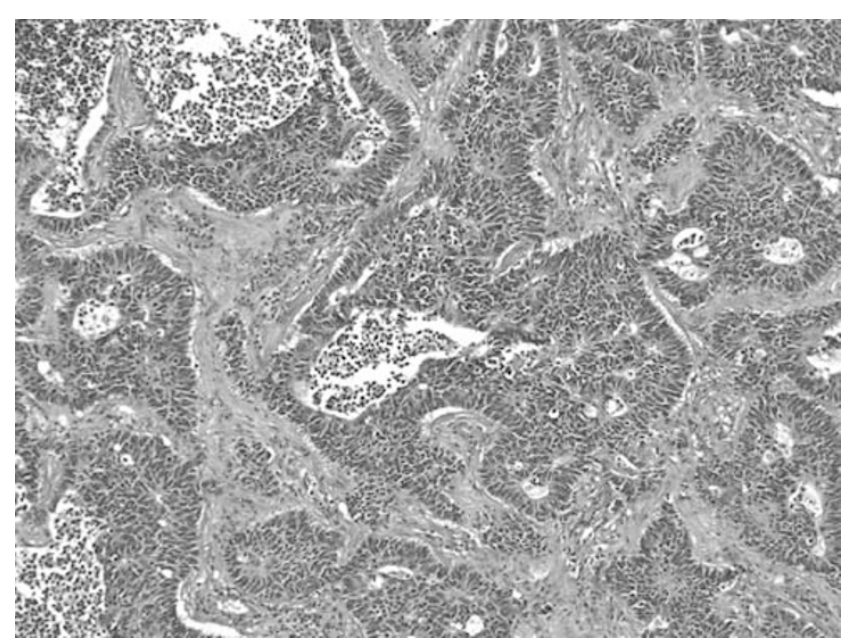

Figure 1 Pulmonary intestinal-type adenocarcinoma. Low magnification demonstrates a garland-like arrangement of cells arranged in lobules with central necrosis (A\&E, $\times 40)$.



Figure 2 Pulmonary intestinal-type adenocarcinoma. A cribriform arrangement of neoplastic cells with luminal spaces filled with mucinous material and necrotic cells was often seen. An intense inflammatory host reaction was also notable $(\mathrm{H} \& \mathrm{E}, \times 40)$.

chromatic nuclei were round to cigar shaped and oriented basally (Figure 4). Mitoses were frequent (average 14/10 high power field; range 8-132), including atypical forms. While extracellular diastase resistant periodic acid Schiff and mucicarmine-positive mucin was seen in all six cases, occasional goblet cells were seen in only three cases in a patchy distribution. Signet ring cells were not present. Focal clear cell change was seen in one case, and abundant mucin production was observed in two instances. Squamous differentiation and papillae were not observed.

A consistent feature of these tumors was a dramatic host stromal response consisting of a dermoplastic spindle cell reaction accompanied by a diffuse intense lymphoplasmacytic reaction with occasional lymphoid follicles. Also notable was the



Figure 3 Pulmonary intestinal-type adenocarcinoma. 'Dirty necrosis' was present in the lumens of the tubular glands $(\mathrm{H} \& \mathrm{E}, \times 40)$.

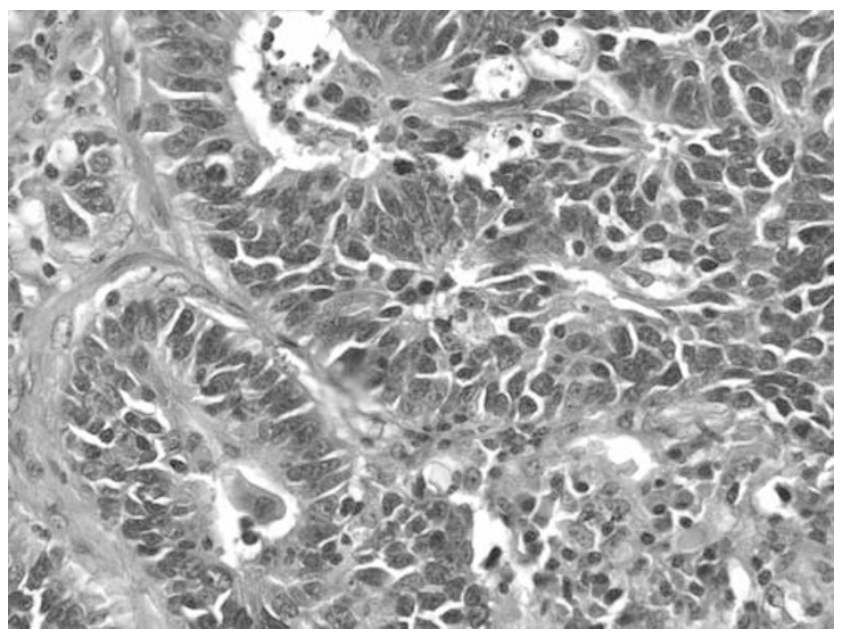

Figure 4 Pulmonary intestinal-type adenocarcinoma. The neoplastic cells were columnar, with oval nuclei, dense chromatin, and apically oriented cytoplasm $(\mathrm{H} \& \mathrm{E}, \times 200)$.

absence of peripheral lepidic growth of neoplastic cells at the edges of the nodules.

\section{Immunohistochemistry}

The immunohistochemical results of the six cases of pulmonary intestinal-type adenocarcinoma compared to an age- and sex-matched group of 10 patients with metastatic colorectal adenocarcinoma to lung are shown in Table 3. All six lung intestinaltype adenocarcinomas expressed TTF-1 and failed to express CDX-2 (Figure 5). Cytokeratin 7 was expressed in all cases while cytokeratin 20 was not (Figures 6 and 7). MUC1 was present in all six pulmonary intestinal-type adenocarcinomas while MUC 2 and MUC5 AC was expressed in two and one 
Table 3 Comparison of immunohistochemical results of pulmonary intestinal-type adenocarcinoma to metastatic colonic adenocarcinoma



Pulmonary intestinal-type adenocarcinoma

$\begin{array}{llllllll}1 & 3 & 0 & 0 & 3 & 4 & 0 & 0 \\ 2 & 4 & 1 & 0 & 3 & 4 & 0 & 0 \\ 3 & 1 & 0 & 0 & 4 & 4 & 0 & 0 \\ 4 & 4 & 0 & 0 & 4 & 4 & 0 & 0 \\ 5 & 4 & 1 & 1 & 4 & 4 & 0 & 0 \\ 6 & 4 & 0 & 0 & 4 & 4 & 0 & 0\end{array}$

Metastatic colorectal adenocarcinoma

$\begin{array}{rlllllll}1 & 0 & 0 & 2 & 0 & 0 & 4 & 4 \\ 2 & 0 & 0 & 2 & 0 & 0 & 4 & 4 \\ 3 & 0 & 0 & 2 & 0 & 0 & 4 & 3 \\ 4 & 0 & 0 & 1 & 1 & 0 & 4 & 4 \\ 5 & 0 & 0 & 2 & 0 & 0 & 4 & 4 \\ 6 & 0 & 0 & 3 & 0 & 0 & 4 & 3 \\ 7 & 0 & 0 & 2 & 3 & 0 & 4 & 4 \\ 8 & 0 & 1 & 2 & 0 & 0 & 4 & 4 \\ 9 & 0 & 0 & 0 & 1 & 0 & 4 & 3 \\ 10 & 0 & 0 & 2 & 0 & 0 & 4 & 4\end{array}$

Staining key: $0-$ negative $(<4 \%$ of cells positive); $1-5-24 \%$ positive cells; $2-25-49 \%$ positive cells; $3-50-74 \%$ positive cells; $4-75-100 \%$ positive cells.

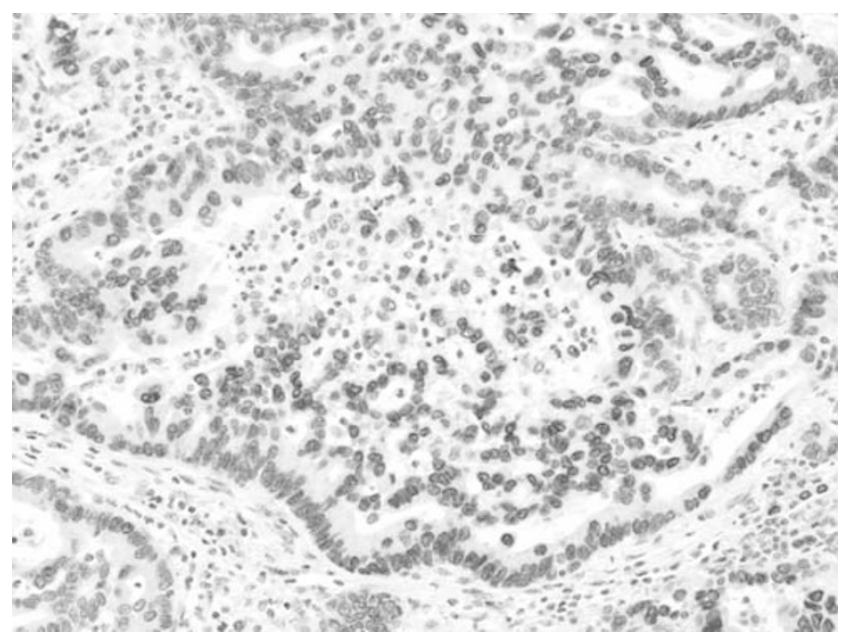

Figure 5 Pulmonary intestinal-type adenocarcinoma. Immunostains for TTF-1 showed strong nuclear positivity (immunoperoxidase, $\times 200$ ).

case of pulmonary intestinal-type adenocarcinoma, respectively, in a small number of cells (Figure 8). In contrast, the metastatic colorectal adenocarcinomas failed to express TTF-1 while uniformly expressing CDX2, and consistently expressed CK20 in the absence of CK7. MUC1 was infrequently and weakly expressed in colonic adenocarcinomas $(3 / 10)$, in contrast to the pulmonary intestinal-type adenocarcinomas. By the same token, colonic adenocarcinomas usually expressed MUC 2 (10/10) while lung intestinal-type adenocarcinomas did not (1/6). These immunohistochemical studies demonstrated that despite the histologic similarity of pulmonary intestinal-type adenocarcinomas to intestinal neo-



Figure 6 Pulmonary intestinal-type adenocarcinoma. Cytokeratin 7 was strongly expressed (immunoperoxidase, $\times 200$ ).

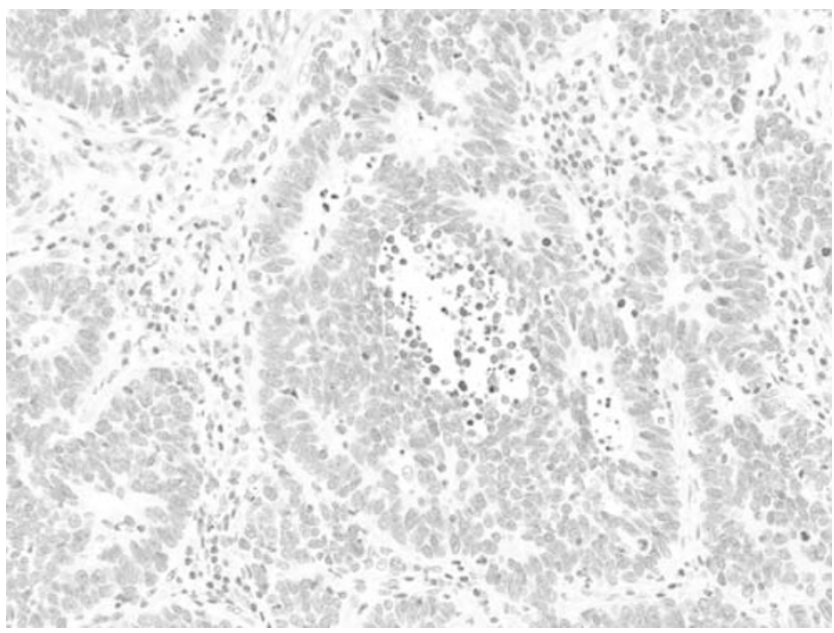

Figure 7 Pulmonary intestinal-type adenocarcinoma. Cytokeratin 20 was not expressed, including an absence in mucin secreting and goblet cells (immunoperoxidase, $\times 200$ ).

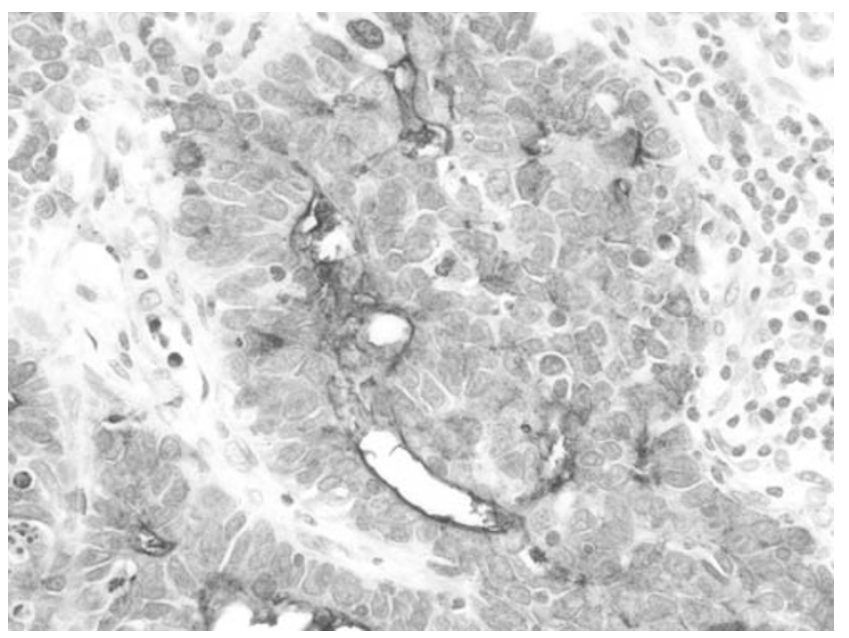

Figure 8 Pulmonary intestinal-type adenocarcinoma. Only MUC1 was consistently expressed in the neoplastic cells, predominantly at the luminal surfaces (immunoperoxidase, $\times 400$ ). 
Table 4 Comparison of histologic and immunohistochemical features of mucinous/intestinal-type adenocarcinomas of lung ${ }^{\mathrm{a}}$

\begin{tabular}{|c|c|c|c|c|c|}
\hline & $\begin{array}{c}\text { Pulmonary intestinal-type } \\
\text { adenocarcinoma }\end{array}$ & $\begin{array}{c}\text { Goblet cell } \\
\text { mucinous ADCA }\end{array}$ & $\begin{array}{l}\text { Signet ring } \\
\text { ADCA }\end{array}$ & $\begin{array}{c}\text { Mucinous variant } \\
\text { BAC }\end{array}$ & $\begin{array}{c}\text { Mucinous } \\
\text { cystadenocarcinoma }\end{array}$ \\
\hline Histology & $\begin{array}{l}\text { Cribriform architecture; } \\
\text { 'dirty necrosis', stratified } \\
\text { columnar cells }\end{array}$ & $\begin{array}{l}\text { Goblet cells } \\
\text { floating in pools } \\
\text { of mucin }\end{array}$ & $\begin{array}{l}\text { Signet ring } \\
\text { cells } \\
\text { in pools } \\
\text { of mucin }\end{array}$ & $\begin{array}{l}\text { Lepidic, non- } \\
\text { invasive growth } \\
\text { of goblet cells }\end{array}$ & $\begin{array}{l}\text { Large mucin filled cysts } \\
\text { lined by goblet and } \\
\text { stratified cells }\end{array}$ \\
\hline \multicolumn{6}{|c|}{ Immunohistochemistry } \\
\hline TTF-1 & + & $+1-$ & + & Usually - & $+1-$ \\
\hline CD7 & + & $+1-$ & + & + & NA \\
\hline CK20 & - & + & - & + & NA \\
\hline MUC1 & + & NA & NA & NA & NA \\
\hline MUC2 & $+1-$ & + & - & - & NA \\
\hline MUC5AC & $+1-$ & - & + & + & NA \\
\hline SPA & NA & $+1-$ & - & - & NA \\
\hline CDX-2 & - & + & - & - & NA \\
\hline
\end{tabular}

aeferences: 2-11.

ADCA—adenocarcinoma; BAC—bronchioloalveolar carcinoma; NA-not applicable.

plasms, there was little evidence of antigenic similarity.

\section{Discussion}

This study is the first to report a group of pulmonary adenocarcinomas that are histologically similar to high-grade sinonasal adenocarcinomas and metastatic colorectal carcinoma that have been christened 'intestinal-type adenocarcinoma' in other sites. ${ }^{13-15}$ While these primary pulmonary tumors are histologically similar to gastrointestinal carcinoma, they fail to demonstrate immunohistochemical markers associated with enteric tumors.

The lung represents a common site of metastasis for colorectal carcinoma and the separation of primary from secondary tumors is essential for patient management. Pulmonary intestinal-type adenocarcinomas are morphologically identical to metastatic intestinal carcinoma including the characteristic garland-like arrangement of columnar cells with luminal 'dirty necrosis', as initially described by Tsao. ${ }^{4,12}$ Pulmonary intestinal-type adenocarcinomas are well-circumscribed masses lacking significant lepidic growth, and are associated with a prominent lymphoplasmacytic infiltrate. While the morphology of intestinal-type adenocarcinomas resembles colorectal adenocarcinoma, the immunohistochemical profile of TTF-1, CDX-2, cytokeratin 7 and 20, and cytoplasmic mucins clearly demonstrate an absence of enteric differentiation, unlike colorectal and upper respiratory tract sinonasal adenocarcinoma. ${ }^{14,15,27,28}$ Historical markers utilized to separate primary lung from metastatic colonic adenocarcinoma are very effective in separating the two neoplasms-pulmonary intestinal-type adenocarcinoma are TTF-1, cytokeratin 7, MUC1 positive, and CDX2, cytokeratin 20, and MUC2 negative, while metastatic colonic adenocarcinoma shows reversed pattern of immunostaining.
The addition of pulmonary intestinal-type adenocarcinomas to the growing list of mucin-producing lung adenocarcinomas raises an interesting morphologic and immunohistochemical dichotomy (Table 4). Rossi et $a l^{3}$ in an excellent study of mucinous carcinomas of lung, reported that the majority of colloid (mucinous) adenocarcinomas of lung, particularly the goblet cell type, expressed both CDX-2 and TTF-1, and also expressed CK20. They, and others, have also noted that mucinous bronchioloalveolar adenocarcinoma and signet ring adenocarcinoma of lung fail to express CDX2 with the former showing frequent expression of CK20 but absence of TTF-1. ${ }^{6,8,19,27-29,31,32}$ These studies suggest that the expression of enteric markers is related to mucinous differentiation by neoplastic cells particularly goblet cells. Why goblet cell differentiation in goblet cell type colloid carcinoma should have a different phenotype from mucinous variants of bronchio alveolar carcinoma or pulmonary intestinal-type adenocarcinoma is unclear. What is clear in this study is that pulmonary intestinal-type adenocarcinoma is of higher grade, lacks significant goblet cell differentiation, and fails to display enteric markers. This includes a minority of cells in pulmonary intestinal-type adenocarcinomas showing focal mucinous and goblet cell differentiation.

In summary, this report details six cases of primary lung adenocarcinoma, histologically identical to metastatic colorectal adenocarcinoma. While the morphology is similar, immunophenotypic studies show respiratory tract rather than enteric differentiation, unlike high-grade sinonasal intestinal-type adenocarcinoma or goblet cell type colloid carcinoma of lung.

\section{Acknowledgements}

We thank Diana Winters for secretarial assistance and Tom Bauer for photographic aid. 


\section{References}

1 Travis WD, Colby TV, Corrin B, et al. Histological typing of lung and pleural tumors, 3rd edn. Springer Verlag: Berlin, 1999, pp 31-46.

2 Dixon AY, Moran JF, Wesselius LJ, et al. Pulmonary mucinous cystic tumor. Am J Surg Pathol 1993;17: 722-728.

3 Rossi G, Murer B, Cavazza A, et al. Primary mucinous (so-called colloid) carcinomas of the lung. A clinicopathologic and immunohistochemical study with special reference to CDX-2 homeobox gene and MUC2 expression. Am J Surg Pathol 2004;28:442-452.

4 Ishibashi $\mathrm{H}$, Moriya T, Matsuda $\mathrm{Y}$, et al. Pulmonary mucinous cystadenocarcinoma. Ann Thorac Surg 2003;76:1738-1740.

5 Kragel PJ, Devaney KO, Meth BM, et al. Mucinous cystadenoma of the lung. Arch Pathol Lab Med 1990;114:1053-1056.

6 Maeshima A, Miyagi A, Hirai T, et al. Mucin-producing adenocarcinoma of the lung, with special reference to goblet cell type adenocarcinoma: immunohistochemical observation and Ki-ras gene mutation. Pathol Int 1997;47:454-460.

7 Moran CA, Hochholzer L, Fishback N, et al. Mucinous (so-called colloid) carcinomas of lung. Mod Pathol 1992;5:634-638.

8 Kish JK, Ro JY, Ayala AG, et al. Primary mucinous adenocarcinoma of the lung with signet-ring cells: a histochemical comparison with signet-ring cell carcinomas of other sites. Hum Pathol 1989;20:1097-1102.

9 Castro CY, Moran CA, Flieder DG, et al. Primary signet ring cell adenocarcinomas of the lung: a clinicopathological study of 15 cases. Histopathology 2001;39: 397-401.

10 Merchant SH, Amin MB, Tamboli P, et al. Primary signet-ring cell carcinoma of lung. Immunohistochemical study and comparison with non-pulmonary signet-ring cell carcinomas. Am J Surg Pathol 2001; 25:1515-1519.

11 Hayashi H, Kitamura H, Nakatani Y, et al. Primary signet-ring cell carcinoma of the lung: histochemical and immunohistochemical characterization. Hum Pathol 1999;30:378-383.

12 Lash RH, Hart WR. Intestinal adenocarcinomas metastatic to the ovaries. Am J Surg Pathol 1987;11: 114-121.

13 Barnes L. Intestinal-type adenocarcinoma of the nasal cavity and paranasal sinuses. Am J Surg Pathol 1986;10:192-202.

14 Cathro HP, Mills SE. Immunophenotypic differences between intestinal-type and low-grade papillary sinonasal adenocarcinomas. An immunohistochemical study of 22 cases utilizing CDX2 and MUC2. Am J Surg Pathol 2004;28:1026-1032.

15 Franchi A, Massi D, Palomba A, et al. CDX-2, cytokeratin 20 immunohistochemical expression in the differential diagnosis of primary adenocarcinomas of the sinonasal tract. Virchows Arch 2004;445:63-67.

16 Franchi A, Moroni M, Massi D, et al. Sinonasal undifferentiated carcinoma, nasopharyngeal-type undifferentiated carcinoma, and keratinizing and nonkeratinizing squamous cell carcinoma express different cytokeratin patterns. Am J Surg Pathol 2002; 26:1597-1604.
17 Yatabe Y, Koga T, Mitsudomi T, et al. CK20 expression, CDX2 expression, K-ras mutation, and goblet cell morphology in a subset of lung adenocarcinomas. J Pathol 2004;203:645-652.

18 Lau SK, Luthringer DJ, Eisen RN. Thyroid transcription factor-1: a review. Appl Immunohistochem Mol Morphol 2002;10:97-102.

19 Lau SK, Desrochers MJ, Luthringer DJ. Expression of thyroid transcription factor-1, cytokeratin 7, and cytokeratin 20 in bronchioloalveolar carcinomas: an immunohistochemical evaluation of 67 cases. Mod Pathol 2002;15:538-542.

20 Almeida R, Silva E, Santos-Silva F, et al. Expression of intestine-specific transcription factors, CDX1 and CDX2, in intestinal metaplasia and gastric carcinomas. J Pathol 2003;199:36-40.

21 Gendler SJ, Lancaster CA, Taylor-Papadimitriou J, et al. Molecular cloning and expression of human tumor-associated polymorphic epithelial mucin. J Biol Chem 1990;265:15286-15293.

22 Hanski C, Hofmeier M, Schmitt-Graff A, et al. Overexpression or ectopic expression of MUC2 is the common property of mucinous carcinomas of the colon, pancreas, breast, and ovary. J Pathol 1997;182: 385-391.

23 Ho SB, Niehans GA, Lyftgoft C, et al. Heterogeneity of mucin gene expression in normal and neoplastic tissues. Cancer Res 1993;53:641-651.

24 Lopez-Ferrer A, Curull V, Barranco C, et al. Mucins as differentiation markers in bronchial epithelium. Squamous cell carcinoma and adenocarcinoma display similar expression patterns. Am J Respir Cell Mol Biol 2001;24:22-29.

25 Yamamoto H, Bai Y-Q, Yuasa Y. Homeodomain protein CDX2 regulates goblet-specific MUC2 gene expression. Biochem Biophys Res Commun 2003;300: 813-818.

26 Yu C-J, Yang P-C, Shun C-T, et al. Overexpression of MUC5 genes is associated with early post-operative metastasis in non-small-cell lung cancer. Int J Cancer 1996;69:457-465.

27 Loy TS, Calauce RD. Utility of cytokeratin immunostaining in separating pulmonary adenocarcinomas from colonic adenocarcinomas. Am J Clin Pathol 1994;102:764-767.

28 Kummar S, Fogarasi M, Canova A, et al. Cytokeratin 7 and 20 staining for the diagnosis of lung and colorectal adenocarcinoma. Br J Cancer 2002;86:1884-1887.

29 Shrestha B, Ebihara Y, Osakabe Y, et al. Immunohistochemical, ultrastructural and molecular study of well differentiated adenocarcinomas of the lung predominantly composed of goblet cells. Lung Cancer 1998;22:103-117.

30 Dacic S, Finkelstein SD, Sasatomi E, et al. Molecular pathogenesis of pulmonary carcinosarcoma as determined by microdissection-based allelotyping. Am J Surg Pathol 2002;26:510-516.

31 Goldstein NS, Thomas M. Mucinous and nonmucinous bronchioalveolar adenocarcinomas have distinct staining patterns with thyroid transcription factor and cytokeratin 20 antibodies. Am J Clin Pathol 2001;116:319-325

32 Shah RN, Badve S, Papreddy K, et al. Expression of cytokeratin 20 in mucinous bronchioloalveolar carcinoma. Hum Pathol 2002;33:915-920. 